\title{
A 5-aza-2'-deoxycytidine/valproate combination induces cytotoxic T-cell response against mesothelioma
}

\author{
S. Leclercq*\#, F. Gueugnon*,\#, B. Boutin*, F. Guillot*, C. Blanquart*, A. Rogel*, \\ M. Padieu*, D. Pouliquen*, J-F. Fonteneau* and M. Grégoire*
}

ABSTRACT: Malignant pleural mesothelioma (MPM) is an aggressive tumour with a limited response to conventional therapy. The aim of this study was to evaluate the anticancer effect of a DNA methyltransferase inhibitor, 5-aza-2'-deoxycytidine (5-azaCdR), and two histone deacetylase inhibitors, valproic acid (VPA) and suberoylanilide hydroxamic acid (SAHA).

Human mesothelioma cells were treated with each epigenetic drug, either alone or in combinations. The cytotoxic effects on treated cells and the expression of specific tumour antigens were evaluated. The recognition of treated cells by a specific CD8+ T-cell clone was also measured. Additionally, the effect of combined treatments was tested in a murine model of mesothelioma.

We showed that VPA and SAHA synergised with 5-azaCdR to kill MPM cells and induce tumour antigen expression in the remaining living tumour cells. As a consequence, tumour cells expressing these antigens were recognised and lysed by specific CD8+ cytotoxic T-cells. In vivo, treatment with 5-azaCdR/VPA inhibited tumour growth, and promoted lymphocyte infiltration and an immune response against tumour cells.

Appropriate epigenetic drug combinations, in addition to inducing mesothelioma cell death, also affect the immunogenic status of these cells. This property could be exploited in clinical investigations to develop MPM treatments combining chemotherapeutic and immunotherapeutic approaches.

KEYWORDS: 5-aza-2'-deoxycytidine, immunotherapy, mesothelioma, suberoylanilide hydroxamic acid, tumour antigen, valproic acid

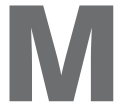
alignant pleural mesothelioma (MPM) is an aggressive tumour of the pleura that is usually associated with chronic asbestos exposure [1]. Worldwide, the incidence of MPM is increasing and is expected to peak around the year 2020 [2]. MPM treatments include chemotherapy, radiotherapy and surgery, but are of limited efficacy, necessitating the development of new therapeutic strategies. Numerous pre-clinical and clinical studies have proved that hypomethylating drugs, such as 5aza-2'-deoxycytidine (5-azaCdR; decitabine), and histone deacetylase (HDAC) inhibitors, such as valproic acid (VPA; depakine) and suberoylanilide hydroxamic acid (SAHA; vorinostat), have potent anticancer activity and promising therapeutic potential [3-11].

The DNA methyltransferase (DNMT) inhibitor decitabine allows the expression of silenced genes through the demethylation of $\mathrm{CpG}$ islands. This drug has recently demonstrated clinical efficacy in the treatment of haematopoietic malignancies [12].
The use of HDAC inhibitors aims to block chromatin compaction due to histone deacetylation, thereby increasing gene expression [13]. Among HDAC inhibitors, depakine and vorinostat are currently being evaluated, alone and in combination, as cytotoxic agents for MPM treatment $[8,9,14]$. In these clinical studies of MPM, and for many others cancer types, decitabine and HDAC inhibitors are being evaluated for their ability to slow down tumour progression by inducing cell cycle arrest, differentiation and/or apoptosis.

In addition, these drugs may also have an impact on the immune response. As spontaneous regression has been observed in mesothelioma patients with infiltration of tumour-specific lymphocytes [15], immunotherapy strategies for the treatment of MPM should be considered [16]. However, the candidate antigens that can be targeted in MPM are poorly defined. One way to bypass this lack of identified antigens for MPM is to force tumour cells to express tumour-associated antigens
AFFILIATIONS

*INSERM, U892, Institut de Recherche Thérapeutique, Université de Nantes, Nantes, France. ${ }^{\#}$ Both authors contributed equally to this work.

CORRESPONDENCE

M. Grégoire

INSERM

U892

IRT UN

8 quai Moncousu

BP70721

44007 Nantes Cedex 1

France

E-mail: marc.gregoire@

nantes.inserm.fr

Received:

May 252010

Accepted after revision:

March 292011

First published online:

May 032011

European Respiratory Journal Print ISSN 0903-1936 Online ISSN 1399-3003 
(TAAs). With the aim of favouring TAA expression, it has been shown that hypomethylating drugs and/or HDAC inhibitors, in addition to restoring a normal epigenetic status in cancer cells, can also induce tumour antigen expression [17-21].

The aim of our investigation was to demonstrate the combined effect of the epigenetic drugs, DNMT and HDAC inhibitors, on both cell toxicity and new expression of TAAs that could activate a cytotoxic T-cell response. Thus, we investigated the toxicity of 5-azaCdR, VPA and SAHA, alone and in sequential combinations, on human MPM cell lines. The effects of these drugs on the expression of several cancer testis antigens (CTAs) (such as NY-ESO-1 (New York oesophageal cancer), and MAGE-A1 and A3 (melanoma-associated antigens)), which are of increasing interest as immunotherapeutic targets, were also analysed, as well as recognition of treated cells by cytotoxic T-cells. Our study showed that VPA and SAHA trigger MPM cell death, and synergise with 5-azaCdR to induce NY-ESO-1 expression in the remaining living cells, which became sensitive to lysis mediated by NY-ESO-1specific cytotoxic T-cells. Additionally, using a mouse model of mesothelioma, we report in vivo tumour regression associated with lymphocyte infiltrates after sequential 5azaCdR and VPA treatment. These infiltrates contained CD8a+ lymphocytes able to secrete interferon (IFN)- $\gamma$ in response to tumour cells.

\section{MATERIALS AND METHODS}

\section{Cell culture}

Human epithelioid mesothelioma cell lines were established from pleural effusions in our laboratory [22]. The human melanoma cell line M117 was provided by N. Labarrière (INSERM, U892, Nantes, France). Cells were cultured in RPMI1640 medium supplemented with $10 \%$ heat-inactivated fetal calf serum, $2 \mathrm{mM}$ L-glutamine, $100 \mathrm{IU} \cdot \mathrm{mL}^{-1}$ penicillin and $0.1 \mathrm{mg} \cdot \mathrm{mL}^{-1}$ streptomycin (complete medium). Human mesothelial cells were isolated from normal pleura by enzymatic disaggregation, and cultured in complete medium supplemented with hydrocortisone $\left(0.4 \mu \mathrm{g} \cdot \mathrm{mL}^{-1}\right)$, epidermal growth factor $\left(10 \mathrm{ng} \cdot \mathrm{mL}^{-1}\right)$, insulin $\left(0.5 \mu \mathrm{g} \cdot \mathrm{mL}^{-1}\right)$ and nonessential amino acids. $5 \mathrm{azaCdR}, \mathrm{VPA}$ and cell culture reagents were purchased from Sigma-Aldrich (Saint-Quentin Fallavier, France). SAHA was provided by P. Bertrand (CNRS UMR 6514, University of Poitiers, Poitiers, France). After drug treatments, cell viability was assessed by TO-PRO-3 iodide labelling (Invitrogen, CergyPontoise, France) and flow cytometry analysis.

The human leukocyte antigen (HLA)-A*0201-restricted, NYESO-1(157-165)-specific CD8+ T-cell clone M117.32H was obtained from tumour-infiltrating lymphocytes of melanoma patient 117 and cultured as described by FONTENEAU et al. [23].

\section{RNA extraction and real-time RT-PCR}

Total RNA was extracted with the RNeasy Mini kit (Qiagen, Courtaboeuf, France) according to the manufacturer's protocol. $1 \mu \mathrm{g}$ total RNA was reverse-transcribed using Moloney murine leukaemia virus reverse transcriptase (Invitrogen). PCR reactions were carried out using $10 \times$ QuantiTect Primer Assays (Qiagen) and $\mathrm{RT}^{2}$ Real-Time SYBR-Green/ROX PCR master mix (Tebu-bio, Le-Perray-en-Yvelines, France), according to the manufacturers' instructions.

\section{Activation of HLA-A*0201-restricted, NY-ESO-1-specific CD8+ T-cells}

Tumour cells were co-cultured with NY-ESO-1-specific CD8+ T-cells in complete medium containing $10 \mu \mathrm{g} \cdot \mathrm{mL}^{-1}$ brefeldin A (Sigma-Aldrich) for $5 \mathrm{~h}$ at $37^{\circ} \mathrm{C}$ and washed. Cells were stained with allophycocyanin-conjugated mouse anti-human CD8 and phycoerythrin (PE)-conjugated mouse anti-human IFN- $\gamma$ monoclonal antibodies (BD Biosciences, Le Pont de Claix, France) using methods described by SIGALOTTI et al. [19]. CD8 and IFN- $\gamma$ expression were analysed by flow cytometry.

\section{Cytotoxicity assay}

Tumour cells were incubated with $\mathrm{Na}_{2}{ }^{51} \mathrm{CrO}_{4}$ (PerkinElmer, Courtaboeuf, France) for $1 \mathrm{~h}$ at $37^{\circ} \mathrm{C}$ and either pulsed or not with $10 \mu \mathrm{M}$ NY-ESO-1(157-165) peptide for $1 \mathrm{~h}$ at $4^{\circ} \mathrm{C}$. Cells were subsequently co-cultured with HLA-A*0201-restricted NYESO-1-specific CD8+ T-cells for $4 \mathrm{~h}$ at $37^{\circ} \mathrm{C}$, in triplicate. Each supernatant was collected and added to a scintillation liquid cocktail (OptiPhase Supermix; PerkinElmer) before liquid scintillation counting. The percentage of specific lysis was calculated as $100 \times$ (experimental release - spontaneous release)/(maximum release - spontaneous release). The spontaneous release of ${ }^{51} \mathrm{Cr}$ was determined from target $\mathrm{T}$-cells cultured alone. The maximum release of ${ }^{51} \mathrm{Cr}$ was obtained from target T-cells lysed in medium containing 1\% Triton X-100.

\section{Animal experiments}

The experiments reported here were carried out in compliance with the guidelines of the European Union for the care and use of animals in research protocols. $5 \times 10^{6} \mathrm{AK} 7$ murine mesothelioma cells per mouse [24] were administered intraperitoneally to four groups of C57BL/ 6 mice (Elevage Janvier, Le Genest-StIsle, France) (day 0). Group 1 did not receive any further treatment. Groups 2 and 4 were given three successive i.p. injections of 5 -azaCdR $\left(4 \mathrm{mg} \cdot \mathrm{kg}^{-1}\right)$ at days 7, 9 and 14. VPA ( $5 \mathrm{mM}$ ) was added to the drinking water of mice in groups 3 and 4 from day 10 to day 20. All animals were necropsied on day 22.

\section{Histopathology and immunohistochemistry}

Tumours and tissues were fixed in $4 \%$ formaldehyde in PBS, embedded in paraffin, cut into $5-\mu \mathrm{m}$ sections and stained with haematoxylin-eosin-saffron.

Immunohistochemistry was performed on tumour slices (paraffin-embedded) using standard techniques. The primary antibody, anti-Foxp3 (Abcam, Paris, France), was used at a dilution of 1/100. N-Histofine Simple Stain Mouse MAX Peroxidase (Nichirei Biosciences, Tokyo, Japan) was used as the detection reagent.

\section{IFN- $\gamma$ ELISPOT assay}

Spleens, as well as AK7 tumours, were pooled for each group of mice (control and 5-azaCdR/VPA) and were dissociated using the gentleMACS Dissociator (Miltenyi Biotech, Paris, France), according to the manufacturer's optimised protocols. Cell suspensions were $70-\mu \mathrm{m}$-filtered, aseptically, and red blood cells were lysed with BD Pharm Lyse solution (BD Biosciences). Living cells were labelled with anti-CD8a (Ly-2) MicroBeads (Miltenyi Biotech). CD8a+ cells were positively sorted using MACS columns and a MACS separator (Miltenyi Biotech). CD8a+ splenocytes $\left(5 \times 10^{5}\right.$ cells per well) and CD8a+ tumour-infiltrating lymphocytes $\left(1 \times 10^{5}\right.$ cells per well $)$ were 
cultured in complete medium supplemented with $50 \mu \mathrm{M} 2$ mercaptoethanol (Merck, Nottingham, UK) at $37^{\circ} \mathrm{C}$ in a 96 -well ELISPOT plate for $36 \mathrm{~h}$. The stimulator cells were AK7 cells $\left(5 \times 10^{4}\right.$ cells per well), pre-treated or not with $0.5 \mu \mathrm{M}$ 5 -azaCdR (72 h) and $5 \mathrm{mM}$ VPA (48 h). The ELISPOT assay was performed in triplicate according to the manufacturer's instructions (BD Biosciences). Spots were counted automatically using an ELISPOT plate reader (Autoimmun Diagnostika $\mathrm{GmbH}$, Strassberg, Germany).

\section{Statistical analysis}

Statistical significance was calculated using GraphPad Prism (GraphPad Software Inc., San Diego, CA, USA). Comparisons between groups were made using the Mann-Whitney U-test or Kruskal-Wallis ANOVA followed by Dunn's post-test (multiple comparisons). A two-tailed p-value $<0.05$ was considered as significant.

\section{RESULTS}

Toxic and proliferative effects of 5-azaCdR, VPA and SAHA on MPM cells

Carcinogenesis results from a combination of genetic abnormalities and epigenetic modifications leading to dysregulation of genes involved in cell cycle control and apoptosis. Modifications of chromatin depend on the activities of enzymes such as histone acetyltransferases (HATs), HDACs and DNMTs, which are considered to be good targets for cancer therapy. Thus, we first studied the toxic effects of the HDAC inhibitors VPA and
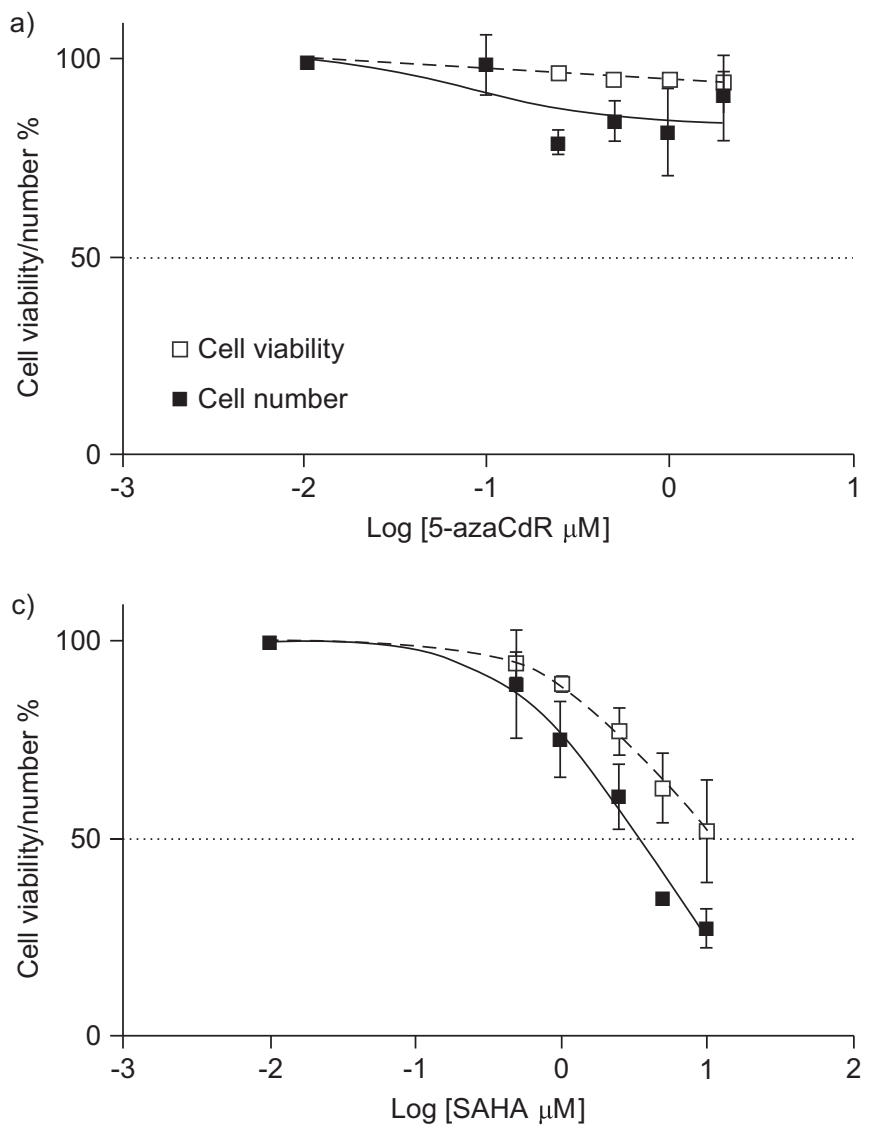

SAHA, and the hypomethylating drug 5-azaCdR on MPM tumour cells, using TO-PRO-3 iodide staining and flow cytometry. These drugs were used at concentrations known to be compatible with their biological activity. After $48 \mathrm{~h}$, VPA or SAHA triggered MPM tumour cell death with a median inhibitory concentration (IC50) of $10 \mathrm{mM}$ and $10 \mu \mathrm{M}$, respectively (fig. 1). This toxic effect was linked to increased MPM cell apoptosis, as indicated by annexin V staining (data not shown). Conversely, 5-azaCdR showed no toxicity and no obvious effect on MPM cell proliferation.

\section{Effects of 5-azaCdR, VPA and SAHA on TAA expression}

MPM displays multiple epigenetic abnormalities that lead to the silencing of tumour suppressor genes [25]. Such observations suggest that MPM may be a good target for epigenetic drugs that would favour the expression of new, tumourassociated genes. Thus, we studied the impact of 5-azaCdR, VPA and SAHA on the expression of three TAAs (NY-ESO-1, MAGE-A1 and MAGE-A3). Using quantitative RT-PCR (RTqPCR), we showed that NY-ESO-1 mRNA was undetectable in all untreated MPM cell lines, and that MAGE-A1 and -A3 mRNAs were also undetectable in half of the tested cell lines. After treatment, 5-azaCdR induced or upregulated the expression of the three antigens tested in a dose-dependent manner (fig. 2). A concentration of $0.5 \mu \mathrm{M} 5$-azaCdR was sufficient to achieve optimal induction levels. In contrast, VPA or SAHA alone had no effect on mRNA expression of the TAA tested (data not shown).

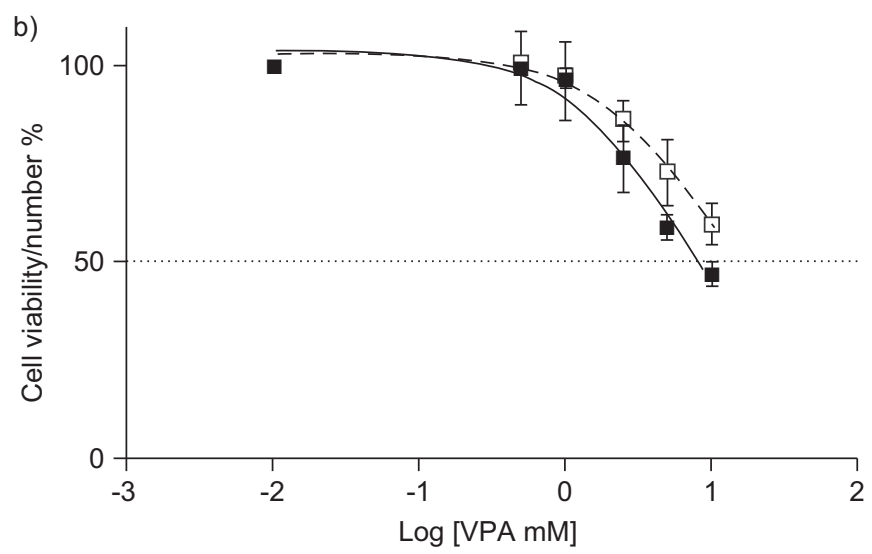

FIGURE 1. Effect of 5-aza-2'-deoxycytidine (5-azaCdR), valproic acid (VPA) and suberoylanilide hydroxamic acid (SAHA) on malignant pleural mesothelioma (MPM) tumour cell viability and proliferation. MPM cell lines were treated with various doses of a) 5-azaCdR, b) VPA or c) SAHA for $48 \mathrm{~h}$. Cell number was measured by counting living cells at the end of the treatments. Cell viability was measured by TO-PRO-3 incorporation and flow cytometry. Data are presented as mean \pm SEM of the four cell lines tested. 

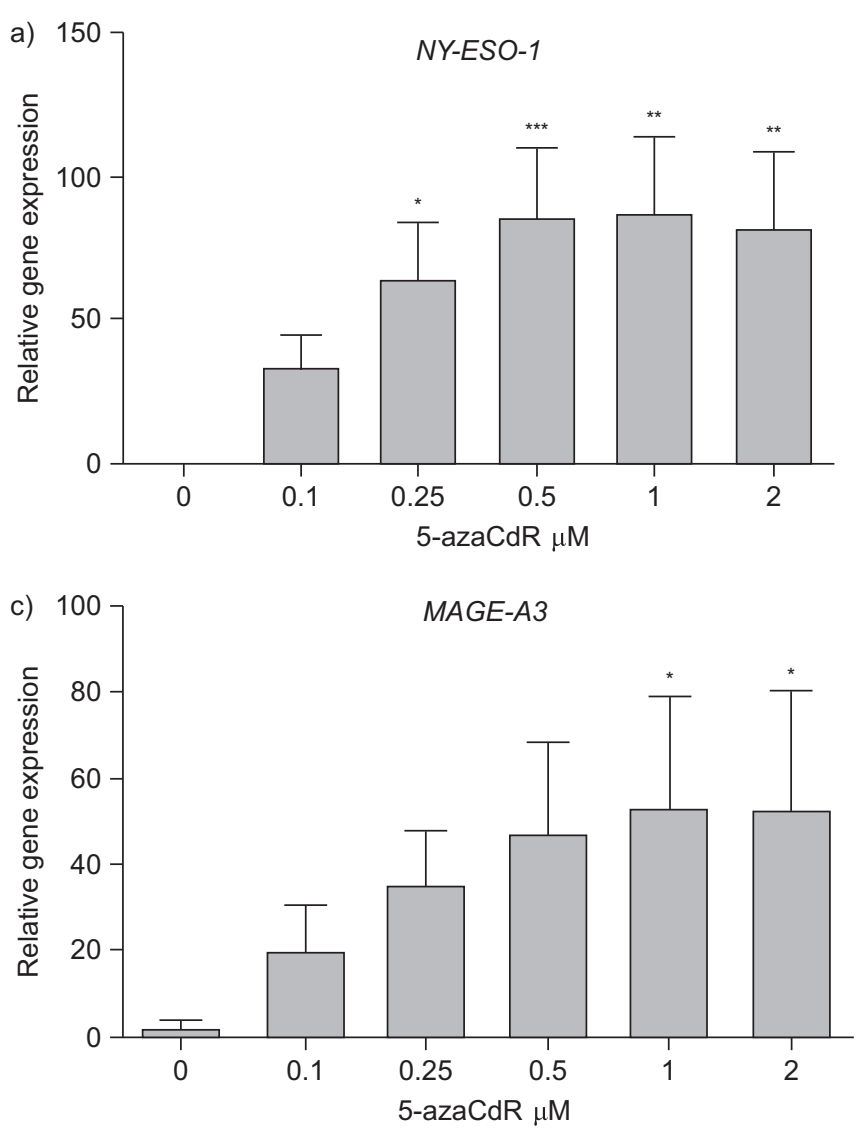

\section{VPA and SAHA enhance the expression of TAAs in MPM tumour cells pre-treated with 5-azaCdR}

Many studies have evaluated the effects of combined treatment of cancer cells with a hypomethylating agent (especially 5azaCdR) and a HDAC inhibitor [26, 27]. Since these drug types affect two cooperative epigenetic mechanisms, we sought to determine the best drug combination schedules. Thus, in order to improve treatment efficiency, we first assessed whether VPA treatment before or after 5 -azaCdR treatment would be more efficient. Two different schedules of treatment with 5-azaCdR and VPA were tested. MPM cell lines were treated with $0.5 \mu \mathrm{M}$ 5-azaCdR followed by $5 \mathrm{mM}$ VPA, or with $5 \mathrm{mM} \mathrm{VPA}$ followed by $0.5 \mu \mathrm{M} 5$-azaCdR (fig. 3a). Analysis of NY-ESO-1 mRNA expression by RT-qPCR showed an induction after both of these sequential treatments. However, treatment with 5-azaCdR/ VPA, as compared with VPA/5-azaCdR, was associated with much higher NY-ESO-1 mRNA expression levels in all MPM cell lines tested. The optimal schedule of sequential 5-azaCdR/ VPA treatment was investigated (fig. 3b). The best inductions of NY-ESO-1 expression were observed after sequential treatments with $0.5 \mu \mathrm{M}$ 5-azaCdR (48 h)/5 mM VPA (48 h) and $0.5 \mu \mathrm{M} 5$ $\operatorname{azaCdR}(72 \mathrm{~h}) / 5 \mathrm{mM}$ VPA $(48 \mathrm{~h})$.

Genetic abnormalities and epigenetic modifications are characteristics of chromatin alteration that lead to carcinogenesis. Thus, epigenetic drug inhibitors should not have an effect on normal cells. The effects of the most effective combination, 5azaCdR/VPA, on NY-ESO-1 expression in normal mesothelial cells (NMCs) were evaluated. NMC primary cultures were obtained from pleural biopsies of patients undergoing cardiac

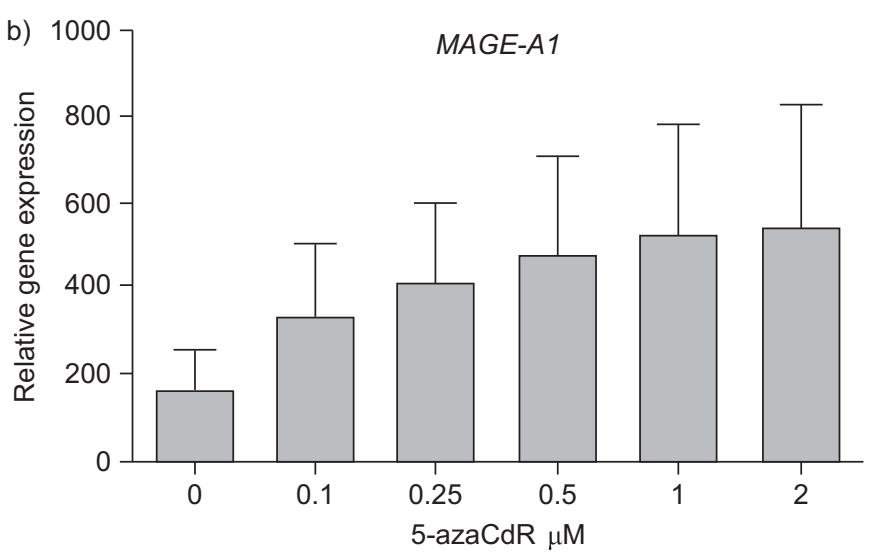

FIGURE 2. Effect of 5-aza-2'-deoxycytidine (5-azaCdR) on cancer testis antigen expression. Malignant pleural mesothelioma cell lines $(n=4)$ were treated with various doses of 5 -azaCdR for $48 \mathrm{~h}$. Suberoylanilide hydroxamic acid and valproic acid alone had no effect (data not shown). a) NY-ESO-1, b) MAGE-A1 and c) MAGE-A3 gene expression was measured by real-time RT-PCR. For each gene, results were normalised to the endogenous reference gene, $\operatorname{RPLPO}(\times 1,000)$. Data are presented as mean \pm SEM of the four cell lines tested. Statistical significance was calculated using Kruskal-Wallis ANOVA followed by Dunn's post-test. *: $p<0.05 ; * *: p<0.01 ; * * *: p<0.001$

surgery. NMC cultures were positive for the normal mesothelium markers calretinin and cytokeratins-5 and -6 (data not shown). NY-ESO-1 mRNA was not detected in NMCs, either before or after treatment with 5-azaCdR/VPA (fig. 3c). Conversely, NY-ESO-1 was induced in MPM-treated cells, but to a lower level than that observed in the melanoma cell line M117. Similar results were obtained for MAGE-A1 and -A3 (data not shown).

In another set of experiments, we compared the effects of the combinations 5-azaCdR/VPA and 5-azaCdR/SAHA on TAA expression and cell proliferation. MPM cells were treated with $0.5 \mu \mathrm{M} 5$-azaCdR and with either $5 \mathrm{mM}$ VPA or $2.5 \mu \mathrm{M}$ SAHA (fig. 4). No effect of 5 -azaCdR on cell proliferation was observed after treatment. Conversely, the combination of 5 -azaCdR with VPA or with SAHA (used at doses below their IC50) led to a $50 \%$ inhibition of cell proliferation $(40 \%$ when the HDAC inhibitor was used alone). However, as previously noted with HDAC inhibitor alone, no complete toxicity was observed with combination treatments. Furthermore, 5-azaCdR/VPA treatment was associated with higher TAA mRNA levels than treatment with 5 -azaCdR alone or the 5-azaCdR/SAHA combination. Thus, we focused on the combination 5-azaCdR/ VPA for subsequent experiments.

\section{HLA-A*0201-restricted, NY-ESO-1-specific CD8+ T-cells respond to all HLA-A*0201+, 5-azaCdR/VPA-treated MPM cell lines}

NY-ESO-1 is considered a very valuable target for T-cell-based immunotherapy [28]. Thus, we evaluated whether the NY-ESO-1 

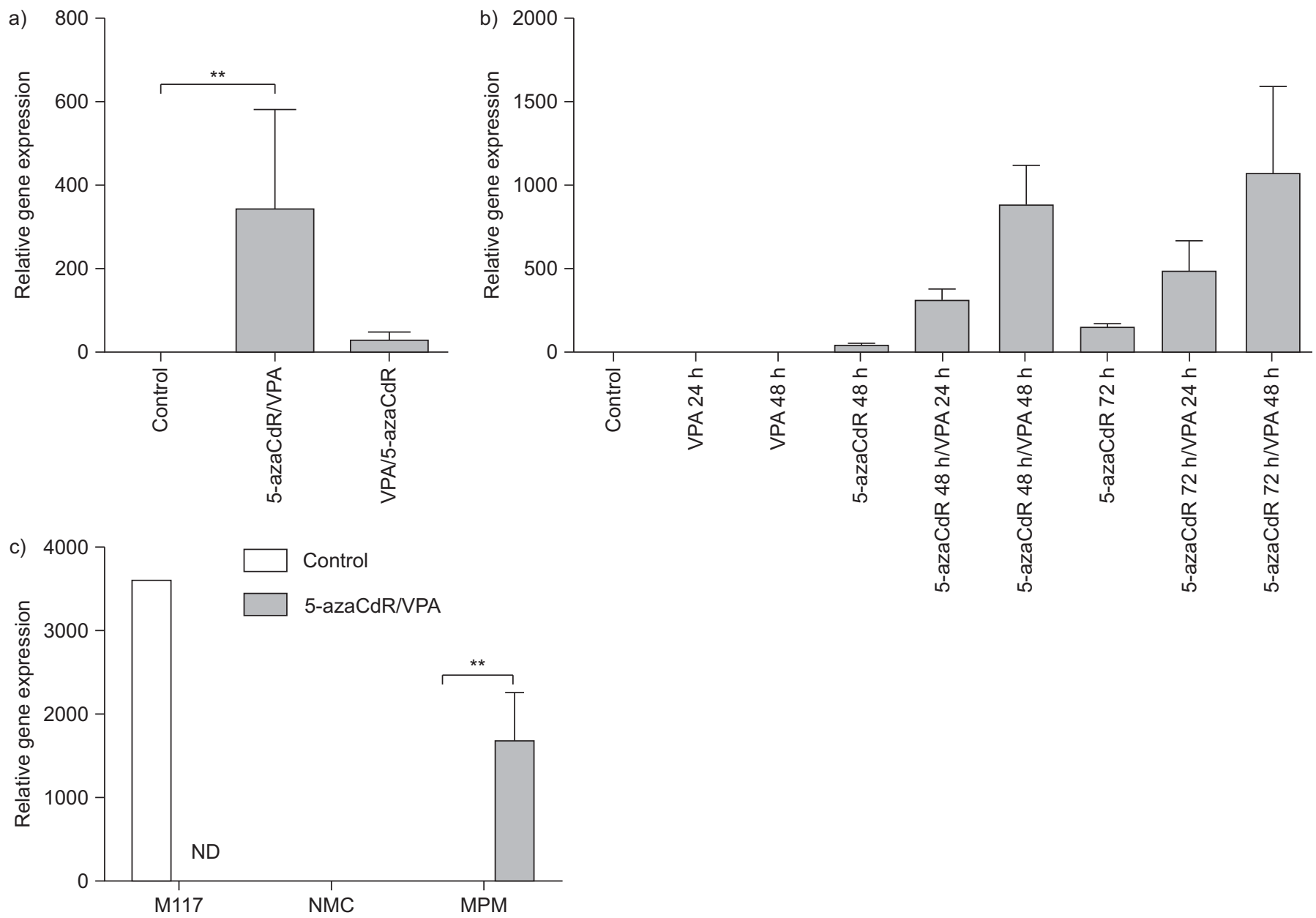

FIGURE 3. Impact of different schedules of 5-aza-2'-deoxycytidine (5-azaCdR) and valproic acid (VPA) administration on NY-ESO-1 expression in malignant pleural mesothelioma (MPM) cells and normal mesothelial cells (NMCs). a) NY-ESO-1 expression was assessed by quantitative RT-PCR (RT-qPCR) in different MPM cell lines ( $n=5$ ) treated sequentially with $0.5 \mu \mathrm{M} \mathrm{5}$-azaCdR for $48 \mathrm{~h}$ and $5 \mathrm{mM}$ VPA for $24 \mathrm{~h}$ (5-azaCdR/VPA), or with $5 \mathrm{mM}$ VPA for $24 \mathrm{~h}$ and $0.5 \mu \mathrm{M} 5$-azaCdR for the next $48 \mathrm{~h}$ (VPA/5azaCdR). b) NY-ESO-1 expression was assessed by RT-qPCR in two MPM cell lines treated with $0.5 \mu \mathrm{M} 5$-azaCdR and 5 mM VPA, alone or in combination, with different time schedules. c) NMCs in primary cultures $(\mathrm{n}=2)$ were treated sequentially with $0.5 \mu \mathrm{M}$ 5-azaCdR for $72 \mathrm{~h}$ and $5 \mathrm{mM}$ VPA for $48 \mathrm{~h}$. NY-ESO-1 expression in NMCs was compared to that obtained in five MPM cell lines, and the melanoma cell line M117 as a positive control. NY-ESO-1 expression was normalised to the endogenous reference gene, RPLPO $(\times 1,000)$. Data are presented as mean \pm SEM. Statistical significance was calculated a) using Kruskal-Wallis ANOVA followed by Dunn's post-test or $c)$ Mann-Whitney U-test. ND: not determined. ${ }^{*}: p<0.01$

expression observed in 5-azaCdR/VPA-treated, HLA-A*0201+ MPM cells was able to promote their recognition by an NYESO-1(157-165)/HLA-A*0201-specific CD8+ T-cell clone. This T-cell clone, M117.32H, was obtained from limiting-dilution cultures of tumour-infiltrating lymphocytes from a melanoma patient and recognised the autologous tumour cell line M117 (N. Labarrière; personal communication). Furthermore, this clone exhibited $100 \%$ staining with PE-conjugated NY-ESO-1(157165)/HLA-A*0201 and no staining with HLA-A*0201 tetramer loaded with an irrelevant peptide (data not shown).

In the first set of experiments, IFN- $\gamma$ production by the CD8+ T-cell clone, in response to an MPM cell line treated, or not, with 5-azaCdR/VPA, was tested (fig. 5a). Untreated and treated tumour cells were washed and then co-cultured with the NY-ESO-1-specific T-cell clone. No T-cell clone response was observed with tumour cells that were not treated with 5azaCdR/VPA. IFN- $\gamma$ production by the clone was observed by intracytoplasmic staining only in response to 5-azaCdR/VPAtreated cells. Under some conditions, IFN- $\gamma$ was added with VPA to the culture medium, in order to increase the expression of HLA class I molecules at the surface of MPM cells (data not shown) and, therefore, their recognition by CD8+ T-cells. As expected, a slightly better activation of the clone was observed (e.g. $\leqslant 32.3 \%$ of cells versus $26.2 \%$ for the MPM cell line meso96) when tumour cells were pre-treated with exogenous IFN- $\gamma$.

The level of activation of the clone in response to 5-azaCdR/ VPA-treated MPM cell lines and its level of recognition of the control autologous M117 melanoma cell line were then compared. All 5-azaCdR/VPA-treated, HLA-A2+ MPM cell lines were recognised by the clone, but at levels lower than the level of recognition of M117 (fig. 5b). As a control, it was also demonstrated that the HLA-A*0201- MPM cell line was not recognised, as it did not express the NY-ESO-1(157-165)-presenting 

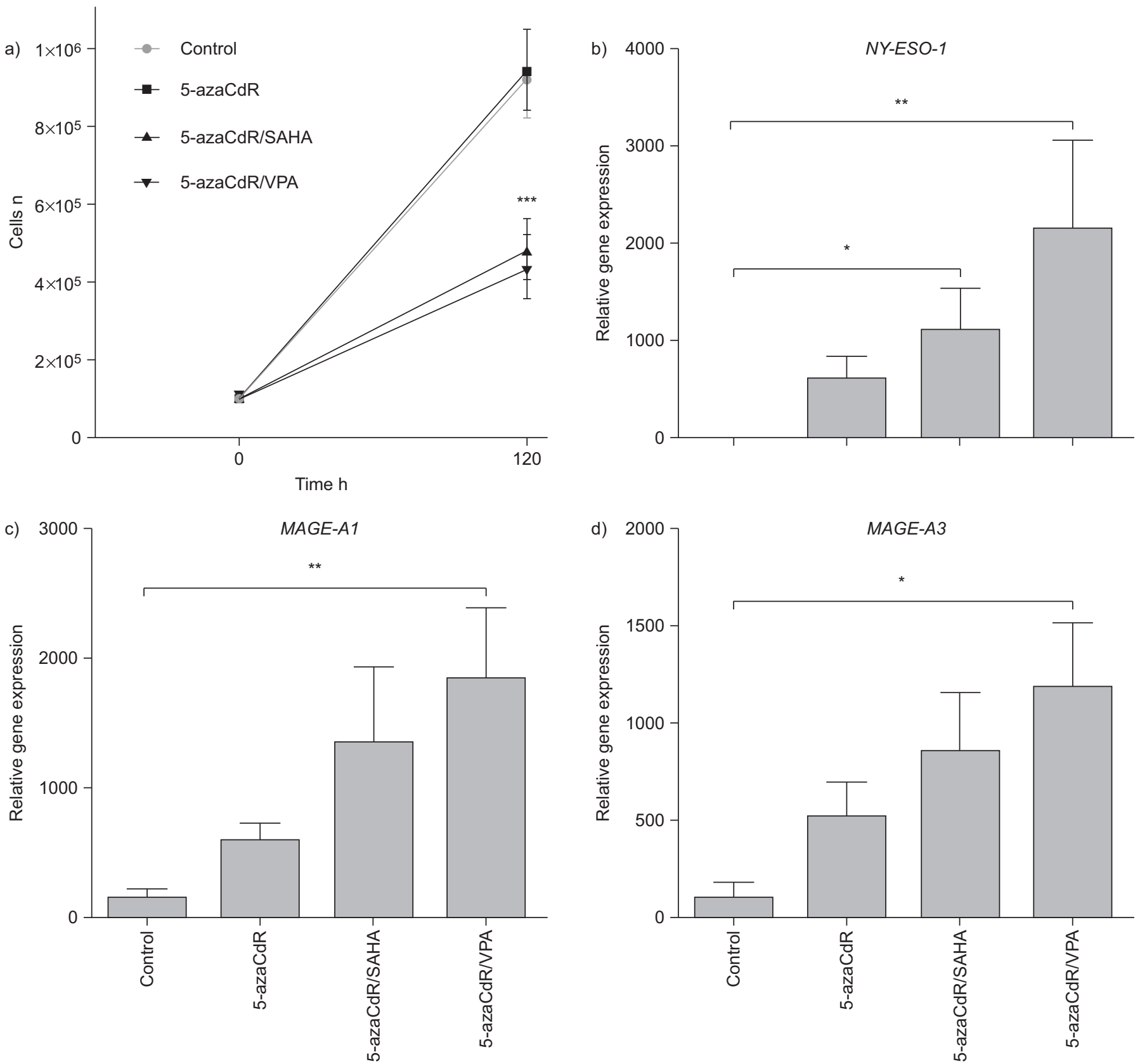

FIGURE 4. Effects of the combinations 5-aza-2'-deoxycytidine (5-azaCdR)/valproic acid (VPA) and 5-azaCdR/suberoylanilide hydroxamic acid (SAHA) on cell proliferation and cancer testis antigen expression. Malignant pleural mesothelioma cell lines were treated sequentially with $0.5 \mu \mathrm{M} 5$-azaCdR for $72 \mathrm{~h}$ and $5 \mathrm{mM}$ VPA or $2.5 \mu \mathrm{M}$ SAHA for $48 \mathrm{~h}$. a) The numbers of living cells were measured at the end of the treatments. Each curve represents the mean \pm SEM growth of the six cell lines tested. b) NY-ESO-1, c) MAGE-A1 and d) MAGE-A3 gene expression were measured by real-time RT-PCR. For each gene, results were normalised to the endogenous reference gene, $R P L P O(\times 1,000)$. Data are presented as mean \pm SEM. Statistical significance was calculated using a) two-way ANOVA, or b-d) Kruskal-Wallis ANOVA followed by Dunn's posttest. *: $p<0.05 ;{ }^{* *}: p<0.01 ; * *: p<0.001$.

HLA-A*0201 molecule. Interestingly, T-cell IFN- $\gamma$ production in response to all treated HLA-A*0201+ cell lines confirmed that 5azaCdR/VPA-treated cell lines express enough NY-ESO-1 protein to efficiently process and present the peptide on their surface and to induce their recognition by an NY-ESO-1-specific CD8+ T-cell clone. Finally, all the clone responses were partially inhibited (mean \pm SEM $56.6 \pm 7.7 \%$ ) by the presence of a blocking anti-HLA-A*0201 mAb (clone BB7.2) in the T-cell clone/MPM cell line co-cultures.
In addition, we tested whether T-cell IFN- $\gamma$ production in response to $0.5 \mu \mathrm{M}$ 5-azaCdR (72 h)/5 mM VPA (48 h)-treated HLA-A*0201+ MPM tumour cells was accompanied by tumour cell lysis by the NY-ESO-1-specific CD8+ T-cells. Cytotoxicity was undetectable in untreated MPM cells, as assessed by ${ }^{51} \mathrm{Cr}$ release (fig. 5c). As expected, MPM cells were lysed when they were pre-treated with $10 \mu \mathrm{M}$ NY-ESO-1(157-165) peptide or when they were treated with 5-azaCdR/VPA. Overall, the clone's cytotoxic activity was well correlated with its IFN- $\gamma$ 
a)
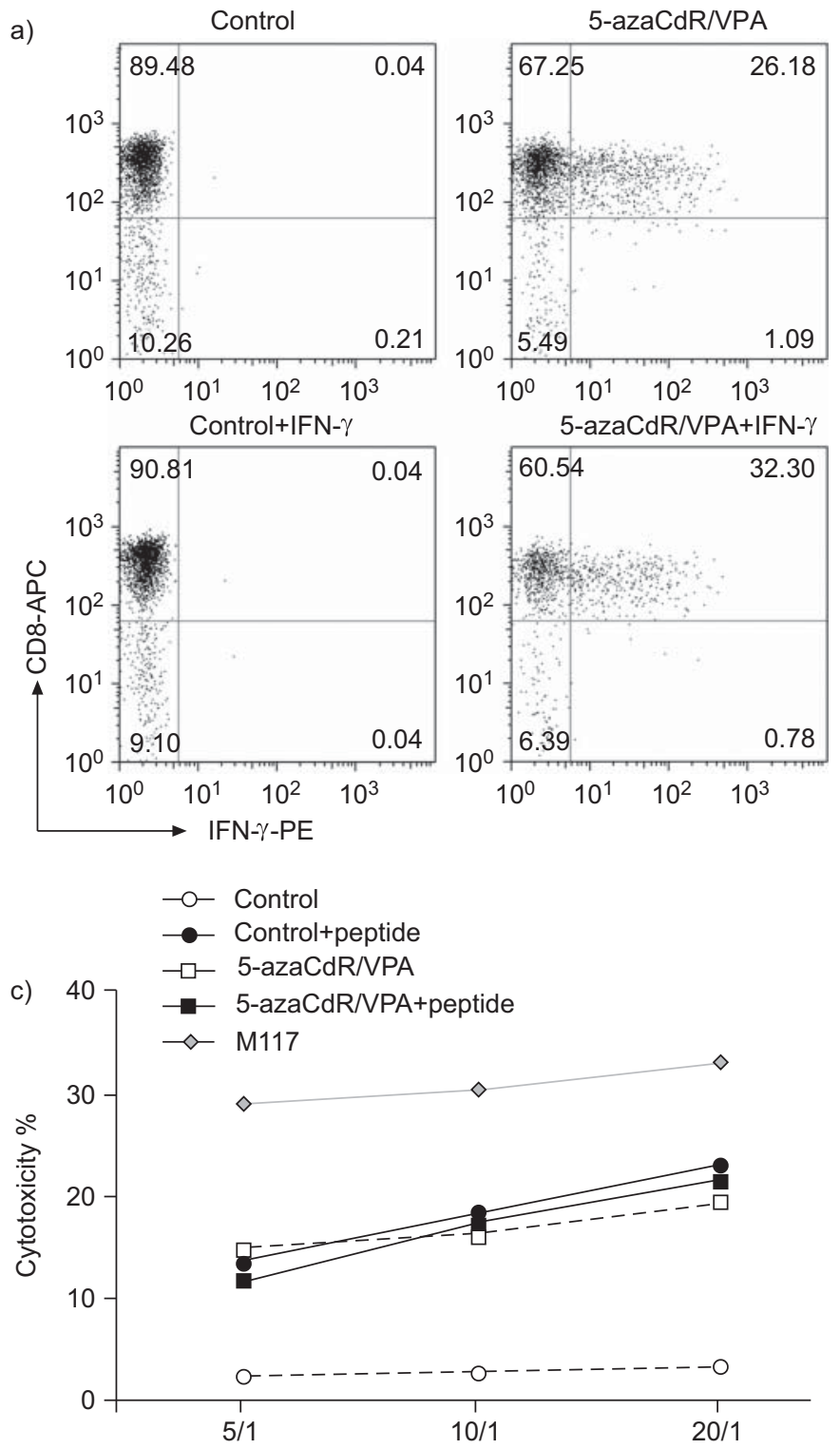

production, suggesting that 5-azaCdR/VPA treatment of MPM tumour cells induces sufficient NY-ESO-1 expression to cause substantial recognition and lysis of tumour cells by NY-ESO-1specific CD8+ T-cells.

VPA, in conjunction with 5-azaCdR, inhibits tumour growth in a murine model of mesothelioma

In order to assess the in vivo efficiency of the combination of 5azaCdR and VPA, we used C57BL/6 mice engrafted with AK7 cells. In pilot studies, we showed that these cells, similarly to human MPM cells, expressed TAAs equivalent to human CTAs, such as the tumour rejection antigen P1A, upon 5-azaCdR/VPA treatment (data not shown). We also determined that i.p. injection of $5 \times 10^{6}$ AK7 cells represented the best tumorigenic dose. The administration schedule of 5 -azaCdR was based on those described by GuO et al. [29], who found that i.p. injections of 5 -azaCdR ( $1 \mathrm{mg} \cdot \mathrm{kg}^{-1}$ body weight) twice daily for five consecutive days were associated with mild toxicity and an induction of P1A. In our experiments, mice received only three

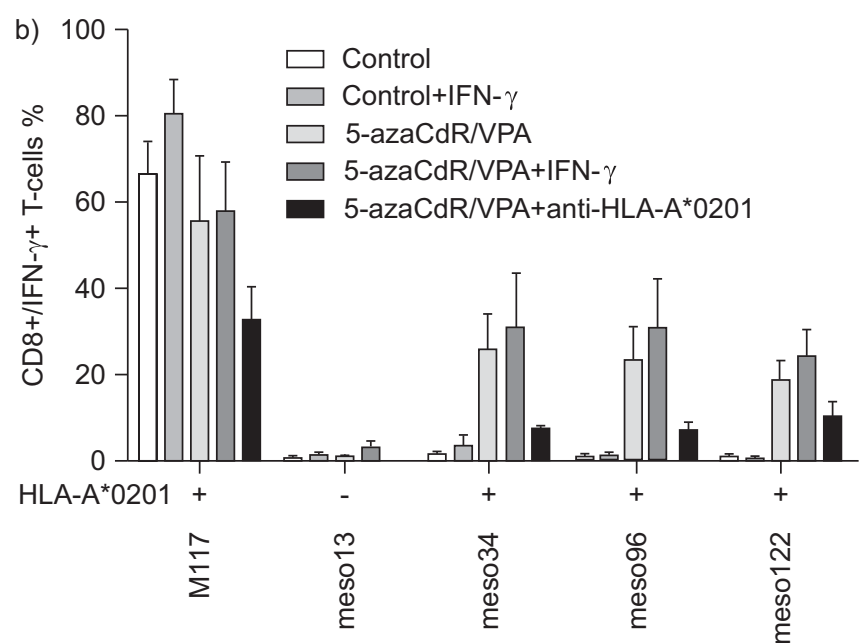

FIGURE 5. Recognition of 5-aza-2'-deoxycytidine (5-azaCdR)/valproic acid (VPA)-treated, human leukocyte antigen (HLA)-A*0201+ malignant pleural mesothelioma (MPM) cell lines by a HLA-A*0201/NY-ESO-1(157-165)-specific CD8+ T-cell clone. a) Interferon (IFN)- $\gamma$ production by the NY-ESO-1-specific CD8+ T-cell clone in response to meso96 treated or not with $0.5 \mu \mathrm{M}$ 5-azaCdR for $72 \mathrm{~h}$ and $5 \mathrm{mM} \mathrm{VPA}$ for $48 \mathrm{~h}$ with or without $500 \mathrm{IU} \cdot \mathrm{mL}^{-1} \mathrm{IFN}-\gamma$ for $48 \mathrm{~h}$. IFN- $\gamma$ production was measured by intracytoplasmic staining of IFN- $\gamma$ and surface staining of $\mathrm{CD} 8$, followed by flow cytometry analysis. b) IFN- $\gamma$ production by the NY-ESO-1-specific CD8+ T-cell clone in response to the autologous melanoma cell line (M117), a HLA-A*0201MPM cell line (meso13) and three HLA-A*0201+ MPM cell lines (meso34, meso96 and meso122), treated or not with $0.5 \mu \mathrm{M}$ 5-azaCdR $(72 \mathrm{~h}) / 5 \mathrm{mM}$ VPA (48 h), with or without IFN- $\gamma(48 \mathrm{~h})$ and a blocking anti-HLA-A*0201 monoclonal antibody. c) Cytotoxic activity of the NY-ESO-1-specific CD8+ T-cell clone in response to the autologous melanoma cell line (M117) and an HLA-A*0201+ MPM cell line (meso96) treated or not (control) with $0.5 \mu \mathrm{M}$ 5-azaCdR $(72 \mathrm{~h}$ )/5 mM VPA (48 h) and pulsed or not with $10 \mu \mathrm{M}$ NY-ESO-1(157-165) peptide. Effector (HLA-A*0201restricted, NY-ESO-1-specific CD8+ T-cells) to target (tumour cells) ratios of 5/1, 10/ 1 and 20/1 were used. Cytotoxic activity was measured by ${ }^{51} \mathrm{Cr}$ release. Experiments were performed in triplicate for each data point. APC: allophycocyanin PE: phycoerythrin.

injections of 5 -azaCdR, but at a higher dose $\left(4 \mathrm{mg} \cdot \mathrm{kg}^{-1}\right)$ and without obviously increased toxicity. Consistent with our in vitro findings, VPA $(5 \mathrm{mM})$ was delivered to mice after the first two injections of 5-azaCdR. The mice were weighed daily, with no differences noted between the groups. Upon completion of the treatment, mice from the treated and untreated groups were killed, and tumour tissues were collected. All the results are summarised in table 1 and representative illustrations for each group are shown in figure 6 . In mice from group 1 (control; $\mathrm{n}=10$ ), the omentum was invaded by AK7 cells, and constituted a hard, white-coloured tissue that was easily isolated from the brown/yellowish soft pancreatic tissue. The tumour mass varied greatly between untreated animals (mean \pm SEM $261.7 \pm$ $43.5 \mathrm{mg}$ ), and the presence of lymphocytes was rare. In animals from group $2(n=6)$, which received only 5 -azaCdR, the tumour mass was slightly reduced $(199.2 \pm 32.5 \mathrm{mg})$ and some areas showed accumulation of non-organised lymphocytes. With VPA alone (group 3; $n=6$ ), the tumour mass was even more reduced $(135 \pm 18.7 \mathrm{mg})$ and important foci of lymphocytes 


\begin{tabular}{|c|c|c|c|}
\hline 5-azaCdR & $199.2 \pm 32.5$ & $+++/+$ & $<1$ \\
\hline VPA & $135 \pm 18.7$ & $++/++$ & 3 \\
\hline 5-azaCdR/VPA & $99.8 \pm 22.1^{*}$ & ++/++ & 6 \\
\hline
\end{tabular}

were observed (containing several regulatory T-cells labelled with Foxp3). Finally, mice receiving the combination of 5azaCdR/VPA $(n=6)$ showed the most significant reduction in tumour mass $(99.8 \pm 22.1 \mathrm{mg} ; \mathrm{p}<0.05)$ and a greater number of lymphocyte aggregates. However, in contrast to group 3, tumour cells were excluded from lymphocyte foci, which contained rare Foxp3+ cells localised at the periphery.

In a second series of experiments, we determined whether 5azaCdR/VPA treatment induces a specific $\mathrm{T}$-cell response against AK7 cells. We isolated CD8a+ T-cells from the spleens of mice having received, or not, the combined treatment $(n=5$ for both). We then stimulated these CD8a+ purified T-cells with AK7 tumour cells (fig. 7a). As determined by ELISPOT assay, the number of IFN- $\gamma$-secreting cells was greater in spleens from 5 -azaCdR/VPA-treated mice: mean \pm SEM $80 \pm 6$ spots per $5 \times 10^{5}$ cells compared with $18 \pm 4$ spots per $5 \times 10^{5}$ cells for untreated mice, suggesting the induction of a tumour cellspecific immune response by the treatment. Furthermore, this response was mainly directed towards treatment-induced tumour antigens. Indeed, the IFN- $\gamma$ response doubled with CD8a+ T-cells from the spleens of treated mice stimulated with AK7 cells that were previously treated with $0.5 \mu \mathrm{M} 5$-azaCdR for $72 \mathrm{~h}$ and $5 \mathrm{mM}$ VPA for $48 \mathrm{~h}\left(154 \pm 9\right.$ spots per $5 \times 10^{5}$ cells $)$, as compared with untreated AK7 cells $\left(80 \pm 6\right.$ spots per $5 \times 10^{5}$ cells). No spots were observed in wells containing medium alone and $12 \pm 4$ spots per $5 \times 10^{5}$ cells were observed in wells containing only T-cells. Most importantly, we succeeded in isolating CD8a+ lymphocytes from the tumours of mice having received the 5-azaCdR/VPA treatment, but not from untreated animals. As for the experiment performed with splenocytes, we observed an increase in the number of T-cells producing IFN- $\gamma$ in response to treated AK7 cells ( $28 \pm 2$ spots per $1 \times 10^{5}$ cells), as compared with untreated AK7 cells $\left(10 \pm 2\right.$ spots per $1 \times 10^{5}$ cells) (fig. $7 \mathrm{~b})$ and medium alone $\left(4 \pm 2\right.$ spots per $1 \times 10^{5}$ cells).

\section{DISCUSSION}

Hypomethylating drugs and HDAC inhibitors are used clinically for their ability to promote growth arrest, differentiation and apoptosis of tumour cells [13, 30]. Decitabine (5azaCdR), an inhibitor of DNMTs, is the most commonly used hypomethylating drug [31]. Depakine (VPA) and vorinostat (SAHA) are two HDAC inhibitors currently being evaluated for MPM treatment $[8,9,14]$. The histone acetylation mechanism involves two enzyme families: HATs and HDACs. HATs transfer acetyl groups to amino-terminal lysine residues in histones, whereas HDACs catalyse the removal of acetyl groups, leading to chromatin condensation and transcriptional repression [32, 33].

Apart from their intrinsic toxic properties, our work demonstrated that epigenetic drugs used alone, or in combination, could have an impact on the expression of TAAs and, therefore, could improve the recognition of tumour cells by cytotoxic Tcells. We focused our attention on CTAs, which are of growing interest as immunotherapeutic targets because of their in vivo immunogenic properties, expression among tumours of different types and absence in normal tissues [28, 34].

Consistent with a previous observation made by SigALOTTI et al. [19], we showed that 5-azaCdR used alone can induce or increase the expression of NY-ESO-1, MAGE-A1 and MAGEA3 in MPM cells of the epithelioid subtype at doses that are not cytotoxic. In contrast to 5-azaCdR, its close analogue 5-azacytidine (vidaza), which is preferentially incorporated into RNA but not DNA, was not efficient in inducing the expression of the CTAs analysed (data not shown). Conversely, VPA or SAHA alone displayed relatively high toxicity on these cells but did not affect CTA expression. However, we showed that these two drugs, used at doses below optimal toxicity, enhanced CTA expression in MPM cells pre-treated with 5 -azaCdR. In addition, the overall toxicity of the combined treatment was slightly increased when compared with the HDAC inhibitor alone. In proliferating cells, pre-treatment with 5-azaCdR induces demethylation of the CpG islands located in the promoters of silenced genes, such as those encoding CTA, as reported for NY-ESO-1 in a glioma cell model [35], and, as a consequence, allows their expression. Thus, the subsequent use of VPA or SAHA, which can directly inhibit HDAC activity and leave the chromatin in an open conformation, enhances the expression of CTAs induced by 5 -azaCdR through a better accessibility of transcription factors to DNA. Importantly, NMCs treated similarly did not express CTAs, such as NY-ESO-1, suggesting that such treatment did not affect the immunogenic status of normal, nonproliferating cells.

Furthermore, we observed that all HLA-A*0201+ MPM cell lines treated with 5-azaCdR/VPA (or 5-azaCdR/SAHA) can be recognised by a CD8+ T-cell clone that is HLA-A*0201restricted and specific to NY-ESO-1(157-165). Hence, de novo synthesised NY-ESO-1 antigen is functionally processed and 

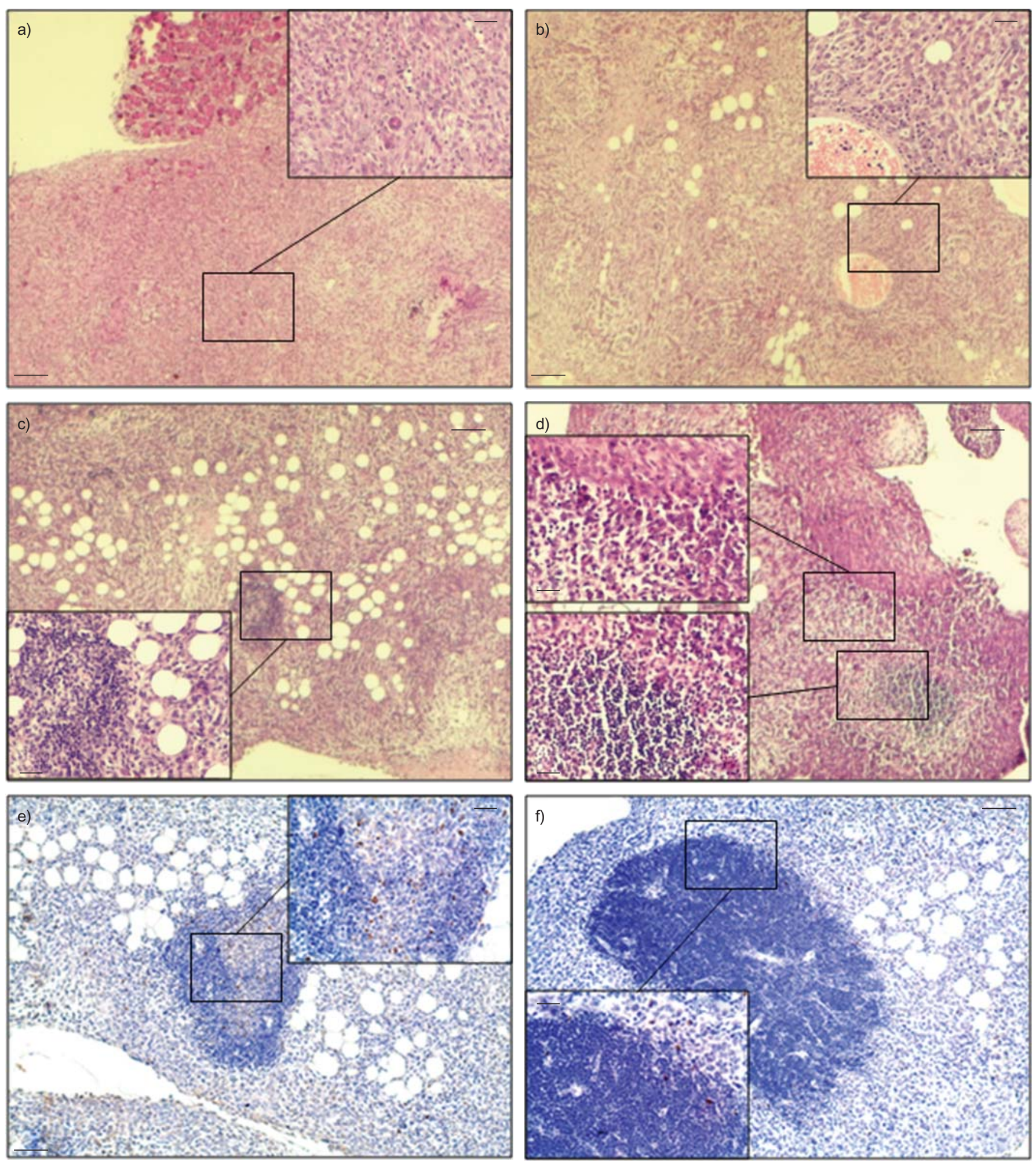

FIGURE 6. Histopathological examination of AK7 tumours implanted in mice. $5 \times 10^{6} \mathrm{AK} 7$ murine mesothelioma cells were injected intraperitoneally into $\mathrm{C} 57 \mathrm{BL} / 6$ mice Mice from a) group $1(n=10)$ had no treatment. Mice from groups b) $2(n=6)$ and d, f) $4(n=6)$ received three injections of 5-aza-2'-deoxycytidine $\left(5\right.$-azaCdR) $\left(4\right.$ mg $\left.\cdot \mathrm{kg}^{-1}\right)$. Valproic acid (VPA) (5 mM) was added to the drinking water of mice from groups $c, e) 3(n=6)$ and d, f) 4. a-d) Tumour sections stained with haematoxylin-eosin-saffron. e, f) Immunohistochemical staining of tumour sections from mice treated with VPA e) alone or f) in combination with 5-azaCdR, using anti-Foxp3 antibodies. Foxp3+ cells appear with a brownish nuclear staining. Scale bars $=250 \mu \mathrm{m}$ (inset $40 \mu \mathrm{m})$ (magnification $4 \times$ (inset $20 \times$ )). 
a)

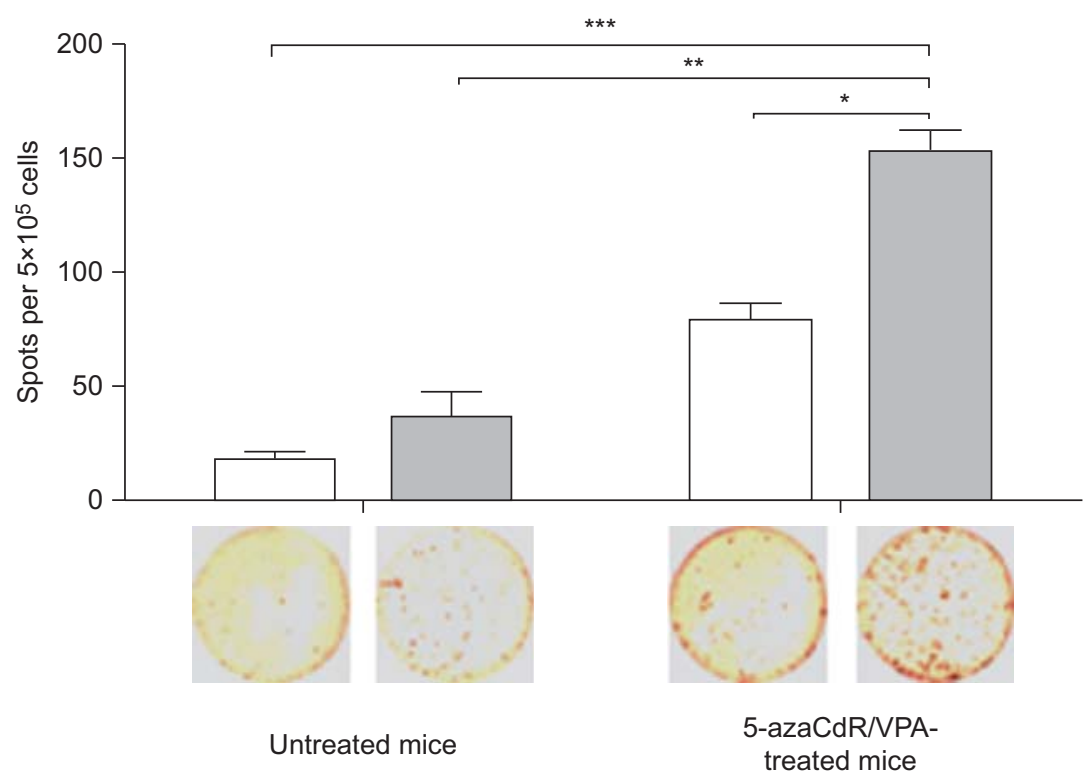

b)

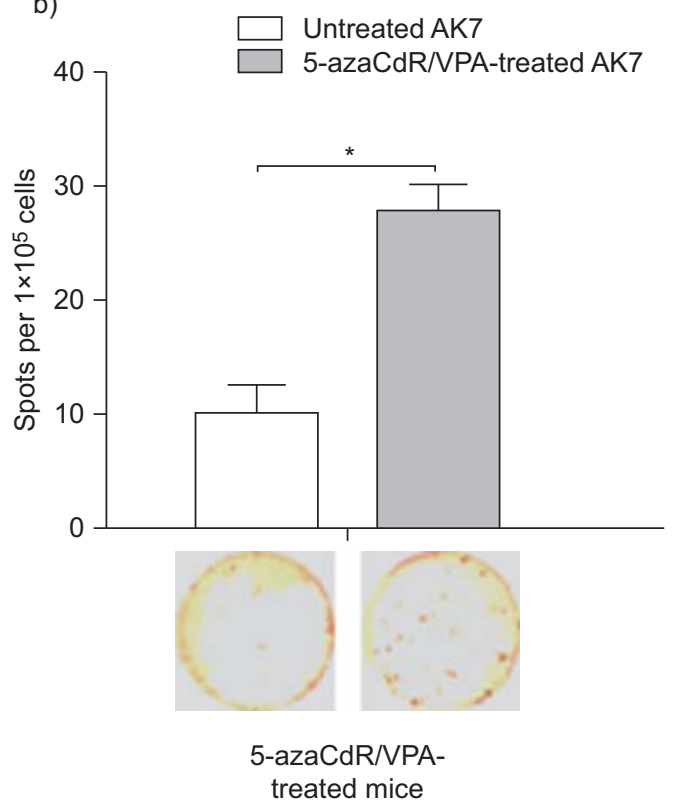

FIGURE 7. T-cell antitumour response in vivo after 5-aza-2'-deoxycytidine (5-azaCdR)/valproic acid (VPA) treatment. CD8a+ T-cells from the a) spleen and b) CD8a+ tumour-infiltrating T-cells from C57BL/6 mice bearing tumours (treated or not with 5-azaCdR/NPA) were stimulated for $36 \mathrm{~h}$ with untreated AK7 cells or 5-azaCdR/VPA-treated AK7 cells. Secretion of interferon- $\gamma$ by CD8a+ cells was measured using an ELISPOT assay. The mean \pm SEM number of spots in triplicate wells was calculated and expressed as number of spots per $5 \times 10^{5}$ or $1 \times 10^{5} \mathrm{CD} 8 \mathrm{a}+$ cells. Significant differences in response were determined using a) Kruskall-Wallis ANOVA followed by Dunn's post-test, or b) Mann-Whitney test. A representative well for each condition is displayed under the corresponding bar of the histogram. ${ }^{*}: p<0.05 ; * *: p<0.01 ; * * *: p<0.001$.

presented on the tumour cell surface through major histocompatibility complex class I molecules. Consequently, we have shown that, in addition to the cytotoxicity induced by the HDAC inhibitor, the sequential 5-azaCdR/VPA treatment induces a specific lysis of MPM cell lines by NY-ESO-1-specific CD8+ T-cells.

Finally, using a murine model of mesothelioma, we demonstrated that such sequential association of treatment with 5azaCdR and VPA could inhibit tumour progression by $\sim 60 \%$ after 3 weeks. This effect is due to both the toxicity of the treatment itself (indicated by active caspase- 3 staining within the tumours of treated mice (data not shown)) and also to the activation of an antitumour immune response. Indeed, although AK7 cells are known to secrete a large amount of transforming growth factor (TGF)- $\beta$ and to promote tolerance towards the tumour [36], we saw large lymphocyte infiltrates within the tumours of treated mice but few Foxp3+ cells. Furthermore, we showed that pools of CD8a+ T-cells isolated from the tumours (and also from the spleens) of treated, compared with untreated, mice contained more T-cells able to recognise AK7 cells. As IFN- $\gamma$ has opposite immunomodulatory effects to TGF- $\beta$, this cytokine may play an important role in the antitumour response observed after 5-azazCdR/VPA treatment.

Although various clinical trials have already shown antitumour activity of 5-azaCdR, SAHA or VPA alone in leukaemias $[3,6,7,11]$, very few data are available concerning the activity of these drugs in patients with MPM [4]. SCHRUMP et al. [4] evaluated the feasibility and toxicity of continuous infusion of 5 -azaCdR alone for $72 \mathrm{~h}$ in 35 patients with lung and oesophageal cancers or MPM in a phase I clinical trial. The authors determined that the maximum tolerated dose of 5 -azaCdR was $60-75 \mathrm{mg} \cdot \mathrm{m}^{-2}$ and, interestingly, that prolonged infusion induced CTA gene expression (NY-ESO-1 and MAGE-A3) in 36\% of patients.

SAHA is the first HDAC inhibitor approved for the treatment of cancer, in particular cutaneous T-cell lymphoma [5]. Its safety is being evaluated in numerous phase I clinical trials for the treatment of solid tumours. Collected safety data showed that the use of SAHA in combination therapies, most commonly at $400 \mathrm{mg}$ daily for 14 days, is generally well tolerated, and preliminary evidence of anticancer activity has been observed across a range of malignancies [11]. Interestingly, in a phase I study, two out of 13 patients with advanced MPM who had progressed after first-line chemotherapy demonstrated a partial clinical response after oral administration of SAHA for several cycles of therapy [9].

Among HDAC inhibitors, VPA is known to be less active than hydroxamic acids, such as SAHA, but its pharmacokinetic properties and bioavailability favour its use as a clinical treatment. For instance, VPA has a longer half-life than SAHA (16-17 $\mathrm{h}$ and 19-47 $\mathrm{min}$, respectively) and its widespread use as an antiepileptic drug over several decades has proven that its side-effects are acceptable in the long term. VPA is currently being tested as an anticancer agent, either alone or in combination with other agents, mostly in haematological diseases [7]. In a phase I/II study, 53 patients with advanced leukaemia were treated with a fixed dose of 5-azaCdR $\left(15 \mathrm{mg} \cdot \mathrm{m}^{-2} \cdot\right.$ day $^{-1} i . v$. for 10 days) administered concomitantly with $50 \mathrm{mg} \cdot \mathrm{kg}^{-1} \cdot \mathrm{day}^{-1} \mathrm{VPA}$, given orally for 10 days [37]. This 
combined 5-azaCdR/VPA treatment was shown to be safe and active, and was also associated with significant DNA hypomethylation, induction of histone acetylation and gene reactivation. Clinical studies with VPA alone or in combination with other agents have also been performed on solid tumours [38]. For example, in a phase I study, patients with advanced solid tumours were treated with VPA by intravenous infusion: consistent with the observations in leukaemia patients, doses $\leqslant 60 \mathrm{mg} \cdot \mathrm{kg}^{-1} \cdot$ day $^{-1}$ for five consecutive days were well tolerated and showed detectable biological activity, i.e. accumulation of hyperacetylated $\mathrm{H} 3$ and $\mathrm{H} 4$ histones in cell lysates of peripheral blood lymphocytes [39]. In the context of MPM, it has been shown recently that VPA improves the proapoptotic effect of pemetrexed/cisplatin, the usual first-line treatment regimen for this tumour, in tumour cells from patients' biopsies and in a mouse model of MPM [8]. The clinical benefit of VPA plus doxorubicin was recently evaluated in a phase II trial (see protocol 01062 at www.elcwp.org). There are currently very few data available concerning the use of 5 -azaCdR and VPA combinations (sequential or concomitant) for the treatment of solid malignancies. Only one clinical trial (phase I) for the treatment of patients with nonsmall cell lung cancer is ongoing (see protocol NCT00084981 at www.clinicaltrials.gov). Notably, in all these studies, patients received 5-azaCdR, SAHA or VPA by intravenous infusion or orally at doses below those used here. However, other administration protocols can be proposed, such as infusion into the pleural cavity in direct contact with MPM tumour cells. This route of injection, which has been used successfully in clinical trials with interleukin-2 [40], may allow the use of higher doses of drugs that are incompatible with systemic administration and may also diminish side-effects in other organs.

Altogether, these clinical trials have allowed the measurement of 5-azaCdR, SAHA and VPA toxicities but, considering our results presented here, the impact of these molecules on the immune response towards cancer cells should be evaluated further. Our investigations have demonstrated that sequential 5 -azaCdR/VPA or 5-azaCdR/SAHA treatments represent potential new strategies to induce MPM cell death and to modulate the immunogenicity of remaining, drug-resistant tumour cells. This work opens up new opportunities for the development of additional MPM treatment strategies that use chemotherapeutic drug combinations, such as 5-azaCdR/VPA or 5-azaCdR/SAHA, to induce MPM cell apoptosis and neoexpression of CTAs, such as NY-ESO-1, in the remaining, apoptosis-resistant tumour cells. These latter cells then become targets for a cytotoxic and TAA-specific immune response. Furthermore, this strategy may bypass the development of antigen-specific tolerance mechanisms that occur when CTAs are expressed by cancer cells during tumour progression. The association of such chemotherapeutic with immunotherapeutic treatments should be evaluated in the future.

\section{SUPPORT STATEMENT}

This study was supported by INSERM, La Ligue Interregionale Contre le Cancer (Vendée, Morbihan, Maine et Loire, Sarthe and Deux Sèvres), La Fondation de l'Avenir, la Fondation pour la Recherche Médicale and the Nantes University Hospital.

\section{STATEMENT OF INTEREST}

None declared.

\section{ACKNOWLEDGEMENTS}

We are grateful to N. Labarrière (INSERM, U892, Nantes, France) for providing the M117 melanoma cell line and the M117.32H T-cell clone, and to P. Bertrand (CNRS UMR 6514, University of Poitiers, Poitiers, France) for the SAHA. We would also like to thank M. Robard and C. Deleine (both Plateforme de Morphologie, IFR26, Université de Nantes, Nantes) for their help with histological analyses, and V. Dehame (INSERM, U892, Nantes, France) for technical assistance.

\section{REFERENCES}

1 Kazan-Allen L. Asbestos and mesothelioma: worldwide trends. Lung Cancer 2005; 49: Suppl. 1, S3-S8.

2 Robinson BW, Musk AW, Lake RA. Malignant mesothelioma. Lancet 2005; 5: 397-408.

3 Wijermans PW, Ruter B, Baer MR, et al. Efficacy of decitabine in the treatment of patients with chronic myelomonocytic leukemia (CMML). Leuk Res 2008; 32: 587-591.

4 Schrump DS, Fischette MR, Nguyen DM, et al. Phase I study of decitabine-mediated gene expression in patients with cancers involving the lungs, esophagus, or pleura. Clin Cancer Res 2006; 12: 5777-5785.

5 Mann BS, Johnson JR, Cohen MH, et al. FDA approval summary: vorinostat for treatment of advanced primary cutaneous T-cell lymphoma. Oncologist 2007; 12: 1247-1252.

6 Garcia-Manero G, Yang H, Bueso-Ramos C, et al. Phase 1 study of the histone deacetylase inhibitor vorinostat (suberoylanilide hydroxamic acid (SAHA)) in patients with advanced leukemias and myelodysplastic syndromes. Blood 2008; 111: 1060-1066.

7 Kuendgen A, Gattermann N. Valproic acid for the treatment of myeloid malignancies. Cancer 2007; 110: 943-954.

8 Vandermeers F, Hubert P, Delvenne P, et al. Valproate, in combination with pemetrexed and cisplatin, provides additional efficacy to the treatment of malignant mesothelioma. Clin Cancer Res 2009; 15: 2818-2828.

9 Krug LM, Curley T, Schwartz L, et al. Potential role of histone deacetylase inhibitors in mesothelioma: clinical experience with suberoylanilide hydroxamic acid. Clin Lung Cancer 2006; 7: 257-261.

10 Paik PK, Krug LM. Histone deacetylase inhibitors in malignant pleural mesothelioma: preclinical rationale and clinical trials. J Thorac Oncol 2010; 5: 275-279.

11 Siegel D, Hussein M, Belani C, et al. Vorinostat in solid and hematologic malignancies. J Hematol Oncol 2009; 2: 31.

12 Plimack ER, Kantarjian HM, Issa JP. Decitabine and its role in the treatment of hematopoietic malignancies. Leuk Lymphoma 2007; 48: 1472-1481.

13 Lane AA, Chabner BA. Histone deacetylase inhibitors in cancer therapy. J Clin Oncol 2009; 27: 5459-5468.

14 Kelly WK, O'Connor OA, Krug LM, et al. Phase I study of an oral histone deacetylase inhibitor, suberoylanilide hydroxamic acid, in patients with advanced cancer. J Clin Oncol 2005; 23: 3923-3931.

15 Robinson BW, Robinson C, Lake RA. Localised spontaneous regression in mesothelioma - possible immunological mechanism. Lung Cancer 2001; 32: 197-201.

16 Gregoire M. What's the place of immunotherapy in malignant mesothelioma treatments? Cell Adh Migr 2009; 4: 153-161.

17 Weber J, Salgaller M, Samid D, et al. Expression of the MAGE-1 tumor antigen is up-regulated by the demethylating agent 5aza-2'-deoxycytidine. Cancer Res 1994; 54: 1766-1771.

18 Ying J, Gao Z, Li $\mathrm{H}$, et al. Frequent epigenetic silencing of protocadherin 10 by methylation in multiple haematologic malignancies. Br J Haematol 2007; 136: 829-832.

19 Sigalotti L, Coral S, Altomonte $\mathrm{M}$, et al. Cancer testis antigens expression in mesothelioma: role of DNA methylation and bioimmunotherapeutic implications. Br J Cancer 2002; 86: 979-982. 
20 Natsume A, Wakabayashi T, Tsujimura $\mathrm{K}$, et al. The DNA demethylating agent 5-aza-2'-deoxycytidine activates NY-ESO-1 antigenicity in orthotopic human glioma. Int J Cancer 2008; 122: 2542-2553.

21 Weiser TS, Guo ZS, Ohnmacht GA, et al. Sequential 5-aza-2 deoxycytidine-depsipeptide FR901228 treatment induces apoptosis preferentially in cancer cells and facilitates their recognition by cytolytic T lymphocytes specific for NY-ESO-1. J Immunother 2001; 24: 151-161.

22 Gueugnon F, Leclercq S, Blanquart C, et al. Identification of novel markers for the diagnosis of malignant pleural mesothelioma. Am J Pathol 2011; 178: 1033-1042.

23 Fonteneau JF, Larsson M, Somersan S, et al. Generation of high quantities of viral and tumor-specific human CD4+ and CD8+ Tcell clones using peptide pulsed mature dendritic cells. J Immunol Methods 2001; 258: 111-126.

24 Moalli PA, MacDonald JL, Goodglick LA, et al. Acute injury and regeneration of the mesothelium in response to asbestos fibers. Am J Pathol 1987; 128: 426-445.

25 Goto Y, Shinjo K, Kondo Y, et al. Epigenetic profiles distinguish malignant pleural mesothelioma from lung adenocarcinoma. Cancer Res 2009; 69: 9073-9082.

26 Cameron EE, Bachman KE, Myohanen S, et al. Synergy of demethylation and histone deacetylase inhibition in the reexpression of genes silenced in cancer. Nat Genet 1999; 21: 103-107.

27 Steiner FA, Hong JA, Fischette MR, et al. Sequential 5-aza 2'deoxycytidine/depsipeptide FK228 treatment induces tissue factor pathway inhibitor 2 (TFPI-2) expression in cancer cells. Oncogene 2005; 24: 2386-2397.

28 Gnjatic S, Nishikawa H, Jungbluth AA, et al. NY-ESO-1: review of an immunogenic tumor antigen. Adv Cancer Res 2006; 95: 1-30.

29 Guo ZS, Hong JA, Irvine KR, et al. De novo induction of a cancer/ testis antigen by 5 -aza-2'-deoxycytidine augments adoptive immunotherapy in a murine tumor model. Cancer Res 2006; 66: 1105-1113.
30 Kristensen LS, Nielsen HM, Hansen LL. Epigenetics and cancer treatment. Eur J Pharmacol 2009; 625: 131-142.

31 Santi DV, Garrett CE, Barr PJ. On the mechanism of inhibition of DNA-cytosine methyltransferases by cytosine analogs. Cell 1983; 33: 9-10.

32 Roth SY, Denu JM, Allis CD. Histone acetyltransferases. Annu Rev Biochem 2001; 70: 81-120.

33 Marks PA, Miller T, Richon VM. Histone deacetylases. Curr Opin Pharmacol 2003; 3: 344-351.

34 Caballero OL, Chen YT. Cancer/testis (CT) antigens: potential targets for immunotherapy. Cancer Sci 2009; 100: 2014-2021.

35 Oi S, Natsume A, Ito M, et al. Synergistic induction of NY-ESO-1 antigen expression by a novel histone deacetylase inhibitor, valproic acid, with 5-aza-2'-deoxycytidine in glioma cells. J Neurooncol 2009; 92: 15-22.

36 Cordier Kellerman L, Valeyrie L, Fernandez N, et al. Regression of AK7 malignant mesothelioma established in immunocompetent mice following intratumoral gene transfer of interferon- $\gamma$. Cancer Gene Ther 2003; 10: 481-490.

37 Garcia-Manero G, Kantarjian HM, Sanchez-Gonzalez B, et al. Phase $1 / 2$ study of the combination of 5 -aza-2'-deoxycytidine with valproic acid in patients with leukemia. Blood 2006; 108: 3271-3279.

38 Duenas-Gonzalez A, Candelaria M, Perez-Plascencia C, et al. Valproic acid as epigenetic cancer drug: preclinical, clinical and transcriptional effects on solid tumors. Cancer Treat Rev 2008; 34: 206-222.

39 Atmaca A, Al-Batran SE, Maurer A, et al. Valproic acid (VPA) in patients with refractory advanced cancer: a dose escalating phase I clinical trial. Br J Cancer 2007; 97: 177-182.

40 Castagneto B, Zai S, Mutti L, et al. Palliative and therapeutic activity of IL-2 immunotherapy in unresectable malignant pleural mesothelioma with pleural effusion: results of a phase II study on 31 consecutive patients. Lung Cancer 2001; 31: 303-310. 